\title{
MAGNEZYUM ALAŞIMLARI VE KULLANIM ALANLARININ INCELENMESİ
}

\author{
Fahrettin ÖZTÜRK ${ }^{1}$ ve İlyas KAÇAR ${ }^{2}$ \\ ${ }^{1}$ Niğde Üniversitesi Mühendislik Fakültesi Makine Mühendisliği Bölümü Niğde e-posta: fahrettin@nigde.edu.tr \\ ${ }^{2}$ Çukurova Üniversitesi Müh- Mim. Fakültesi Makine Mühendisliği Bölümü Adana e-posta: ikacar@cu.edu.tr
}

\section{ÖZET}

Magnezyum alaşımlarının havacılık, uzay ve otomotiv endüstrisinde yapısal malzeme olarak kullanımı gün geçtikçe artmaktadır. Henüz yaygın kullanımda olmaması ve üretiminin pahalı olması nedeniyle üreticilerin sayısı demir ve çelik üreticilerine göre çok daha azdır. Bu durum magnezyum alaşımlarının pahalı olmasının temel sebeplerinden biridir. Bu çalışmada, magnezyum ve alaşımlarının imalat yöntemleri, şekillendirilebilirlik, korozyon direnci, çevreye olan etkileri ve mevcut kullanım alanları incelenmiştir.

Anahtar Kelimeler: Magnezyum, magnezyum alaşımları, hafif malzemeler.

\section{INVESTIGATION OF MAGNESIUM ALLOYS AND THEIR APPLICATIONS}

\begin{abstract}
The use of magnesium alloys in aerospace, space, and automotive industry as structural materials has gradually been increased. Magnesium alloys producers are much less than the iron and steel producers in number due to the alloys are still not widely used and their production cost are high. This is one of main reasons that the prices of the alloys are expensive. In this study, the manufacturing techniques, formability, corrosion resistance, environmental effects of magnesium and its alloys and applications were investigated.
\end{abstract}

Keywords: Magnesium, magnesium alloys, lightweight materials.

\section{GİRiş}

Magnezyum alaşımları, hafiflik ve yüksek özgül mukavemet özelliklerinden (Mukavemet/yoğunluk) dolayı savunma sanayi ve taşımacılık sektöründe özel bir öneme sahiptir [1-6]. Alaşımsız olarak düşük mukavemet ve tokluk değerlerine sahip olduğundan alaşımlandırılarak kullanılmaktadır. Magnezyum ayrıca yüksek 1sıl iletkenlik, yüksek boyutsal kararlılık, iyi elektromanyetik koruma, yüksek sönümleme, iyi işlenebilme ve kolay geri dönüşüm özelliklerine de sahiptir [7-10]. Bu özellikleri $\mathrm{Mg}$ alaşımlarını otomotiv, bilgisayar, havacılık, mobil telefonlar, spor malzemeleri gibi pek çok endüstride değerli kılmaktadır. Düşük ağırlık ve metabolizmaya uyumu açısından implant malzemesi olarak da kullanılmaktadır [11-16]. Ayrıca son yıllarda enerji kaynaklarını daha verimli kullanmak için yapılan çalışmalara hız verilmiştir. Bu kapsamda otomotiv endüstrisi de yakıt sarfiyatını azaltmak amacıyla araçların daha hafif olması yönünde çalışmalar yapmaktadır [17]. En temel olarak da hafif malzemeler üzerinde durulmaktadır.

Mg alaşımları; sırası ile iki harf, iki veya üç haneli rakamlar şeklinde kodlanarak gösterilmektedir [18]. Birinci harfler ana alaşım elementlerini göstermekte ve müteakibindeki rakam haneleri de, bu elementlerin yüzdelerini belirtmektedir. Yüzdeler en yakın tam sayıya yuvarlanarak yazılmaktadır. Sonra gelen tek hanelik son harf eki ise alaşımın en son kalite durumunu göstermektedir. Örneğin AZ91A gösterimi, ana alaşımlama elementleri olarak \%9 (ortalama değer) alüminyum, \%1 (ortalama değer) çinkoyu göstermektedir. Son ek kullanımındaki bir istisna X harfi olup, alfabetik sırada ilerledikçe impuritelerin-kirliliklerin kontrollü olarak alt sınırda olduğunu ifade etmektedir. Çeşitli alaşım elementlerinde kullanılan harfler şunlardır: A: Alüminyum, E: Nadir Toprak elementleri, H: Toryum, K: Zirkonyum, M: Manganez, Z: Çinko, Q: Gümüş.

\section{MAGNEZYUM ALAŞIMLARI VE AĞIRLIK KAZANCI}

Magnezyum alaşımlarının kullanımı, otomobillerin ağırlıklarını yapısal özelliklerden taviz vermeden büyük oranda azaltabilmektedirler. Alaşım elementlerinden Al, mukavemeti; Zn, tokluğu; Mn, ise korozyona karşı dayanıklılığı arttırmaktadır. Fakat Zn miktarındaki artış sıcak kırılganlığa neden olmaktadır [19]. Günümüzde 
alaşım elementleri olarak mikro gözeneği azaltmak için nadir toprak metalleri, tane inceltme için Zr, yükssek sıcaklık özelliklerini geliştirilmek için $\mathrm{Ag}$ veya $\mathrm{Cu}$, sürünme özelliklerini iyileştirmek için ise Th katılmaktadır [1]. Magnezyum, alüminyumdan $\% 35$ daha hafif bir metaldir. Günümüzde iyi sürünme ve korozyon direnci, deformasyon kabiliyeti ve yeni şekillendirme teknikleri için yeni $\mathrm{Mg}$ alaşımlarının geliştirilmesi yönündeki araştırmalara hız verilmiştir. Yapılan çalışmalarda fiyat ekonomisi göz önünde bulundurulmaktadır. $\mathrm{Mg}-\mathrm{Zn}-\mathrm{Al}$ (ZA) üçlü alaşımı ise en yaygın kullanılan ve geliştirmek için üzerinde çalışılan alaşım gurubudur. Bu grup içerisinde de en yaygın olarak kullanılan alaşım AZ91'dir. Zhang ve Couture [20] bu grubun mikro yapı özelliklerini, çekme ve sürünme direncini, küçük miktarlarda $\mathrm{Ca}$ ve $\mathrm{Sr}$ ilavesinin çekme ve sürünme özelliklerine etkisini incelemişlerdir. Zn:\%10-12, Al:\%2-4 içeren alaşımın çekme özelliklerinin AZ91'e yakın olduğunu, \%4 Al içeren diğer bir alaşımın ise toplam sürünme direnci ve minimum sürünme hızlarının AZ91'e göre dikkate değer bir biçimde daha az ve bu özelliğin de artan sıcaklıklardaki uygulamalar için uygun olduğunu göstermişlerdir. Ca ve Sr ilavesinin sürünme özelliklerini iyileştirdiği ve bu iyileştirmede Ca'un daha etkili olduğu da tespit edilmiştir.

Alaşımların çalışma esnasında uygun miktarda enerjiyi absorbe edebilmeleri gerekmektedir. Bundan dolayı Al içeriğinin daha az olmasına çalışılmıştır. Örneğin AM50 (\%5 Al) özellikle darbe altında daha toktur. Yapılan pek çok çalışmada korozyon dirençleri de incelenmiştir. Yttrium ilavesinin sürünme direncini artırdığı ve bu konuda $\mathrm{Mn}$ ve Al den daha etkili olduğu, tane sınırlarında zengin faz oluşturduğu [21-23], \%0.2 Ce ilavesinin saf Mg ve Mg-3Al-1Zn alaşımına göre daha kolay haddelenebilir olduğu [24], homojenleştirme ve ekstrüzyon şartlarının iyileştirilmesinin mikro yapıyı iyileştirdiği ve şekillendirilebilirliği artırdığı [25-26] açıklanmıştır.

Lazerle yüzey üzerinde yapılan ergitme işlemleri yüzeyin daha fazla korozyon direncine sahip olmasını ve mikro sertlik değerinde büyük artışlar sağlamaktadır [27-29]. Ayrıca klasik kalıba döküm yönteminden farklı olarak uygulanan yarı-katı dökümün korozyona direnci, dentritik mikroyapıya göre daha fazla olmaktadır [3033]. Anodik kaplama ise metal çözülümünü azaltmaktadır [34]. Düşük döküm sıcaklıkları sebebi ile oluşan makro segregasyonlar ve yüzey çatlaklarının azaltılması ile korozyon direnci artmaktadır [35,36]. Mg alaşımlarının viskoelastik davranışları üzerine korozyonun ve gerilmenin birlikte etkisi, korozyon sürünmesi olarak adlandırılmaktadır [37,38]. Al içeriği yapıyı korozyon sürünmesine karşı çok hassas hale getirmektedir. AZ91D ve AM50 alaşımlarının borat çözeltisi içerisinde yapılan korozyon incelemesi neticesinde, yüzeyde oluşan borat aniyon'unun sürünmenin ilk aşamasında korozyon inhibitörü olarak davranması ile metal çözünmesini yavaşlattığı ortaya çıkmıştır.

Magnezyum alaşımları artan sıcaklık altındaki uygulamalarda kullanılmaktadır. Zhu ve ark. [39] uygulamaya bağlı olarak $180,200,250,300^{\circ} \mathrm{C}$ gibi sıcaklık aralıklarında yüksek gerilmelere dayanabilen alaşım geliştirilmesi üzerine yoğunlaşmışlardır. Gutman ve ark. [40] özellikle Al ile olan alaşımların kullanımını incelemişlerdir. MgAl alaşımları mühendislik malzemeleri olarak hafiflik, iyi ısıl ve elektriksel iletim, yüksek korozyon direnci nedeni ile birincil öneme sahiptir. Pres şekillendirme deformasyon sıcaklığı ve şekillendirme hızından etkilendiği için metal şekillendirmede uygun sıcaklık ve deformasyon hızının belirlenmesi oldukça önemlidir.

Çevrenin gaz atıklarından korunması büyük oranda taşımacılık endüstrisi, özellikle kara ve demiryolu taşımacılık araçları tarafından üretilen $\mathrm{CO}_{2}$ emisyonuna bağlı olmaktadır [41]. $\mathrm{CO}_{2}$ emisyonu çevre kirliliği açısından önemli bir kriterdir. Tablo 1 magnezyum da dahil yenilikçi diğer hafif malzemeler ile birlikte ağırlık azaltmanın, yakıt tasarrufunda sağlayabileceği etkiyi göstermektedir. Avrupa ve Kuzey Amerika araç üreticileri kadar yakıt sarfiyatında \%25, $\mathrm{CO}_{2}$ emisyonunda da \% 30'lara varan azalmalara ulaşmışlardır. Alternatif yakıt kaynakları, güç aktarma organları, aerodinamik iyileştirmeler vb. kullanımları ile de çeşitli çözüm yolları mevcut olabilmektedir.

Tablo 1. Yakıt tüketimindeki kazanç [41]

\begin{tabular}{|c|c|c|c|}
\hline & \multicolumn{2}{|c|}{ Yakit Kazancı [\%] } & \multirow{2}{*}{$\begin{array}{l}\text { Yeni malzemelerin } \\
\text { önemi }\end{array}$} \\
\hline & $\begin{array}{l}\text { Kısa-Orta } \\
\text { Dönem }\end{array}$ & Uzun Dönem & \\
\hline Hafif yapı & $3-5$ & $10-15$ & ++ \\
\hline $\mathrm{C}_{\mathrm{w}}$ değeri & 2 & $4-6$ & + \\
\hline Motor/vites & 5 & 10 & \pm \\
\hline Dönmeye direnç & $1-2$ & 3 & + \\
\hline Motor ön Isıtma & 2 & $4-6$ & \pm \\
\hline Ekipman & 2 & 4 & \pm \\
\hline
\end{tabular}

Veriler özellikle otomotiv alanında kullanımının tahmin edilenden daha fazla olacağını göstermektedir. 
Tablo 2. Magnezyumun sağladı̆̆ı ağırlık kazancı [42]

\begin{tabular}{|c|c|c|c|c|c|c|c|c|}
\hline & \multicolumn{8}{|c|}{ Parçalar } \\
\hline & \multicolumn{2}{|c|}{ Motor Bloğu } & \multirow{2}{*}{$\begin{array}{c}\text { Dişli kutusu ve } \\
\text { kavrama } \\
\text { muhafazası(Al alş.) }\end{array}$} & \multirow{2}{*}{$\begin{array}{l}\text { Karter } \\
\text { (Al alş.) }\end{array}$} & \multicolumn{2}{|c|}{4 tekerlek } & \multicolumn{2}{|c|}{ Motor Kızağı } \\
\hline & $\begin{array}{l}\text { Dökme } \\
\text { Demir }\end{array}$ & $\mathrm{Al}$ alş. & & & Çelik & (Al alş.) & Çelik & (Al alş.) \\
\hline Klasik uygulama $[\mathrm{kg}]$ & 32 & 23,5 & $21,5+5$ & 3 & 36 & 23 & 25 & 17,5 \\
\hline Mg Alaşımı [kg] & 19 & 19 & $15+3$ & 2 & 18 & 18 & 15 & 15 \\
\hline Ağırlık kazancı $[\mathrm{kg}]$ & 13 & 4,5 & 6,5 & 1 & 18 & 5 & 10 & 2,5 \\
\hline Ağılılık kazancı [\%] & 40 & 19 & 30 & 33 & 50 & 22,5 & 40 & 30 \\
\hline
\end{tabular}

Tablo 2 nispeten ağır olan araç parçalarının magnezyum alaşımlı olanları ile değiştirildiğinde elde edilecek olan ağırlık kazancını göstermektedir. $\mathrm{CO}_{2}$ emisyonu olarak ifade edilirse $100 \mathrm{~km}$ başına $0,25 \mathrm{lt}$ yakıt kazancı anlamına gelmektedir [42]. Özellikle otomobil üreticileri parça tasarım ve üretiminde kısa orta ve uzun vadeli teknoloji geliştirme çalışmalarına başlamışlardır.

\section{IMMALAT YÖNTEMLERI}

Magnezyum alaşımları genel olarak diğer metaller gibi şekillendirilebilirler. Dövme ve dökme ana grubu içerisinde en çok kullanılan yöntem yüksek basınçlı döküm yöntemi olup, kum kalıba döküm yöntemi ise ağır parçalar için tercih edilen bir yöntemdir. $\mathrm{Zr}$ ise özellikle kum kalıba dökümlü havacılık uygulamalarında kullanılmaktadır. Zr içeren magnezyum alaşımları için alaşım elementleri olarak nadir toprak elementleri, itriyum, gümüş ve çinko özel parçalar, $250-300{ }^{\circ} \mathrm{C}$ aralıklarında iyi sürünme direnci sağlayabilmektedir. Dökme alaşımlar her ne kadar dövmeye göre daha baskın ise de ekstrüzyon, dövme yöntemleri ve sac mamüller ayrıca değişik uygulamalarda kullanılmaya başlanmıştır. Döküm denemeleri yaparak simülasyon sonuçları ile kıyaslamalı çalışmalarında Lohmüller ve ark. [43], AZ91D alaşımını Thixomolding® (Tiksödöküm) yöntemi ile üretmişler ve gözenekliliğin sıcaklıkla değişimini incelemişlerdir. Yaptıkları denemeler sonucunda $580-605^{\circ} \mathrm{C}$ arasındaki sıcaklıklarda katı faz içeriği \%30 dan neredeyse sıfıra düştüğünde, yüksek katı faz içeriğinin ince duvarlı parçalarda gözenekliliği azalttığı ortaya çıkmıştır.

Dövme alaşım teknolojileri gelişim aşamasında olup, piyasa durumu dövme alaşımların çok az kullanıldığını göstermektedir. Fakat son yıllarda otomotiv endüstrisinde dövme alaşımlarına olan ilginin artmakta olduğu tespit edilmiştir.

Özel parçalar için kendine has yöntemler geliştirilmektedir. Yöntemlerden biri, ana elamanın elementin $\mathrm{Mg}$ alaşımı olduğu metal matrisli kompozit (MMK) imalatı olup alaşımlar fiber takviye elamanlarına çok iyi yapışma sağladığından dolayı uygulanabilirliği yüksektir. Dövme magnezyuma $\mathrm{SiC}$, dökme magnezyuma ise cam veya $\mathrm{Al}_{2} \mathrm{O}_{3}$ veya grafit lifleri katılmaktadır. Diğer bir yöntem de sıvı emdirme uygulaması olup, günümüzde Landkof ve ark. [44], havacılık uygulamalarında kullanmışlardır. Lee ve ark. [45] ise, AZ31 ve AZ61 plaka magnezyum alaşımlarının izotermal şekillendirilebilirlik özelliklerini farklı sıcaklık şartlarında araştırarak 0,5, 1,3, 1,7 ve $2 \mathrm{~mm}$ kalınlıklarındaki plakaları uygun şekillendirebilmenin mümkün olduğunu göstermişlerdir.

\section{4. ŞEKILLENDIRILEBILIRLIK}

Havacılık, otomobil ve potansiyel diğer büyük ölçekli magnezyum kullanıcılarınca talep edilen özellikler, alaşım gelişimi gereksinimi ortaya çıkartmıştır. Magnezyum uygulamalarının büyük bir çoğunluğu pres dökümbasınçlı döküm alaşımı olan AZ91 tarafından karşılanmaktadır. Ancak bu alaşım, $130{ }^{\circ} \mathrm{C}$ nin üzerindeki sıcaklıklarda çoğu uygulamalar için yetersiz sürünme direncine sahiptir. $\mathrm{Mg}-\mathrm{Al}-\mathrm{X}$ in gelişimi, süper hafif alaşımların gelişimidir. Li ilavesi mukavemeti azaltmakta fakat tokluğu artırmaktadır.

Son yıllarda oda sıcaklığında kafes yapısı nedeniyle şekillendirilebilme özelliği düşük olan AZ31, AZ61 ve AZ91 alaşımlarının ılık şekillendirilebilme özelliklerinin artırılabilmesi araştırılmaktadır. Bu malzemeler havacılık açısından önemli alaşımlardır [45]. Genel olarak günümüzde yaygın kullanıma sahip olan basınçlı dökümün aksine, magnezyumun dövülerek şekillendirilebilme özelliği ilgi çekmektedir [46]. Sac levhaların şekillendirilebilmelerinde ise oda sıcaklığında zayıf olan şekillendirilebilmenin iyileştirilebilmesi amaçlı olarak yeni yöntemleri tasarlanmakta ve denemeleri yapılmaktadır [47-55]. 


\section{KOROZYON DİRENCI}

Malzemenin zayıf korozyon dayanımı ve aşınma özellikleri, sürünme direnci ve kimyasal aktifliği pek çok alanda kullanımına engel olmaktadır. Özellikle dış ortamlardaki magnezyumun kullanımındaki temel değişimlerden biri zayıf korozyon direncidir.

En sık rastlanan korozyon türü, farklı metallerin temasları ile galvanik çift meydana geldiğinde oluşan elektrokimyasal korozyondur. Yağmur suyu veya yoğuşma suyu gibi suların, malzemelerden iyon çekmesi neticesinde elektrolit haline gelmesi ile anodik eleman korozyona uğramaktadır. Bu da havacılık gibi kritik uygulamalarda hayati rol oynamaktadır.

Havacılık alanında kullanılmakta olan parçalar korozyona dayanıksız olduğundan oldukça kontrollü kullanılmaları gerekmektedir. Alaşımlar; çukurlaşma korozyonuna karşı yüksek oranda hassasiyete sahip olup, oluşan korozyon kar tepecikleri biçiminde beyaz toz şeklinde ve yüzey üzerinde beyaz noktacıklar biçimindedir. Magnezyum çok yüksek aktifliğe sahip bir metal olup diğer birçok metal ile temasında galvanik korozyona neden olmaktadır.

Korozyondan korunma ise tepkimeye müdahale veya koruyucu tabakalarla reaksiyona katılan kısımların ayrılması yoluyla azaltılması veya tamamen ortadan kaldırılması yöntemiyle yapılmaktadır [56]. Magnezyum ve alaşımları üzerinde kimyasal olarak değişmiş bir tabaka oluşturulması korozyon direncini iyileştirmek amaçlı çok önemli bir yüzey işlemidir. Pasivasyon gibi kaplamalar yapılmakta ise de çok etkili olduğu söylenemez. Halen uygulanmakta olan yöntemler; 1sıl püskürtme (alevle, arkla, plazma ile) ile pasivasyon gibi örtücü kaplama (Kromatlama-DIN50939/41, Tagnit Kaplama) yöntemleridir. Ayrica yüzeyden korozyonun kaldırılabilmesi için metal esaslı olmayan temizleyici elemanlar kullanılmaktadır. Motor parçalarının temizlenmesinde ticari çözücüler, kazıyıcılar ve zımpara kullanılır. Bununla birlikte, nihai bakım kimyasal temizleyicilerle sağlanmaktadır. Uygulama olarak imalatçılar genellikle krom oksit ve dikromat içeren banyolar kullanmaktadırlar. Bu malzemelerin çevreye olan olumsuz etkileri nedeni ile daha az zararlı metotların geliştirilmesi gerekmiştir [57-60]. Umehara ve ark. [61] daldırma yöntemi ile şekillendirilen kimyasal dönüşümlü yüzey tabakasının amorf bir yapıya sahip olduğunu ve çok ince magnezyum florür, hidroksitler ve manganez oksit tabakası içerdiğini göstermişlerdir.

\section{HAVACILIKTA MAGNEZYUM}

Havacılık sanayinde kullanılan metallerde istenilen en temel özellikler; hafiflik, dayanıklılık, şok-titreşim ve korozyona karşı dirençtir. Hafiflik, yoğunluğunun azaltılması ile sağlanabilmektedir. Üretimde çoğunlukla alüminyum, çelik, titanyum, magnezyum ve bakır gibi metalik malzemeler kullanılmakta olup, metallerin saf hallerinin düşük mukavemet özellikleri nedeni ile havacılığın özel ihtiyaçlarını karşılanması neredeyse olanaksızdır. Günümüz araştırma ve geliştirme çalışmalarının esası; daha kullanışlı malzemeler elde edebilmek için yeni ve daha önce denenmemiş alaşımların geliştirilmesi çalışmalarıdır. Sektörün yoğun olarak üzerinde iyileştirme yaptığı özellikler şunlardır;

- Yanıcı olmaları,

- Yüzeyine herhangi bir koruyucu kaplama uygulanmadığında, korozif bir ortamda beyaz renkte kümecikler veya noktalar şeklinde korozyona uğramaları,

- Alaşımlarının yüzeylerinde oluşan oksit-karbonat filminin, korozif olmayan ortamlarda dahi yeteri derecede korozyondan korunma sağlayamamaktadır. Uygun koruyucu kaplama uygulandığında korozyon önemli ölçüde azaltılabilmektedir [62].

Hafif parça kullanımı, yakıt tüketimini azaltmak amacına hizmet etmektedir. Hız ve güç gereksiniminin artması sebebiyle de hafiflik yanında daha dayanıklı malzeme kullanımı gerekliliği açıktır. Hava araçlarında $\mathrm{Mg}$ alaşımları üzerine yük binmeyen parçalarda aktif olarak kullanılmaktadır (hidrolik depolar, yakıt depoları, vs.). Quadrant, kuyruk paline hareket vermekte ve üzerine yük binmemektedir. Hidrolik depo ve quadrant AZ91 dökümdür. Depo hidrolik sistemi beslemekte, modele göre hava aracında 1-3 adet bulunmaktadır. Depolar hidrolik akışkanı depolayıp, çalışma şartlarına uygun şekilde hazırlayan tanklardır. Isınan hidrolik akışkanın kolayca soğutulmasını sağlamalıdır. Bu özellikleri ise AZ91 alaşımı gayet iyi bir şekilde sağlamaktadır. MD500, Eurocopter EC120, NH90 ve Sikorsky S92 gibi birçok helikopterin dişli kutularında ZE41 alaşımı, uydu parçaları için de AZ31, AZM ve AZ61 dövme alaşımları yaygın olarak kullanılmaktadır [63].

B-36 bombardıman uçağı toplam 8,6 ton ağırlığında olup yaklaşık 3,4 ton Mg alaşımlarından oluşmaktadır. Eğer Mg yerine Al kullanılmış olsa idi 4,5 ton luk bir ağırlık oluşturacaktı. S55 helikopterlerinde ZW3 alaşımı 
115 kg civarında kullanılmıştır. Tamamen deneysel amaçla imal edilmiş olan F80C tümüyle Mg ile konstrükte edilmiştir [64]. Yeni alaşım çalışmaları ile Mg hakkında bilinen parametreler ve böylece de günümüzde hava araçlarında kullanılabilir magnezyum alaşımlarının sayısı artmaktadır. Diğer avantajı da gürültü ve titreşimin azalmasıdır. Wendt ve ark. [65] AZ91D ile kıyaslandığında mukavemet özelikleri daha iyi olan yeni alaşımlar elde etmişlerdir.

Ağırlık azaltılması temel bir konu olsa da, Mg alaşımları korozyon direncinin zayıf olması nedeniyle geniş bir kullanım alanına sahip değildirler. Uzay endüstrisinde kullanılacak alaşımlar hem mekanik özellikler ve hem de korozyon direnci ile ilgili olan yüksek performans gereksinimini aynı anda sağlamak zorundadır. Günümüzde 20 adet standart $\mathrm{Mg}$ döküm alaşımı mevcut olmasına rağmen, bu alaşımlardan modern havacılık endüstrisinin gereksinimlerini karşılayacak olanlarının azlığı büyük bir engeldir [66].

\section{OTOMOTIV SEKTÖRÜNDE MAGNEZYUM}

Otomobil üreticileri de üstün ve tercih edilebilir özelliklerinden dolayı magnezyum alaşımlı parçalar üretmeye başlamışlardır. BMW firması AZ91 alaşımlı motor bloğu üretmiş ve ticari olarak kullanıma başlamıştır. R6 adını verdikleri motorda, krank kutusu, kam kapağı alüminyum alaşımlı magnezyumdan imal edilmiş olup, emsal motora göre $10 \mathrm{~kg}$ daha hafiflik sağlamaktadır [67].

Volkswagen'in farklı otomobil parçalarının imalatı için kullandıkları çeşitli işlemler Şekil 1'de verilmiştir. Bu şekil, firmanın araçlarında sıcak metal şekillendirme ve tiksödöküm gibi çeşitli yöntemler kullanılarak üretilmiş parçalar kullanma niyetinde olduğunu göstermektedir. Bu gibi alaşım kullanımı genelde üç bölüme ayrılmaktadır. İlki olan kısa vade, kullanılabilir magnezyum alaşımları ve döküm işlerinin geçerli teknolojilerini yükseltmektir. Orta vade, yarı katı döküm ve ekstrüzyon gibi özel döküm tekniklerinin geliştirilmesidir. Uzun dönem ise, yeni alaşım ve yeni imalat teknikleri olarak adlandırılabilecek dövme alaşımlarının geliştirilmesi aşamasıdır.

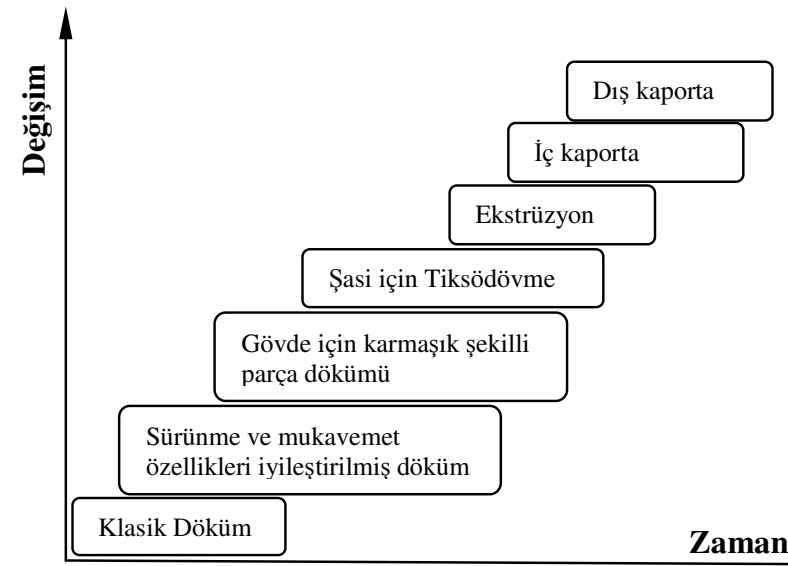

Şekil 1. Magnezyum teknoloji gelişimi için VW stratrejisi [68]

Sektörde sık olarak kullanılan alaşımlar ve özellikleri Tablo 3 te verilmiştir.

Tablo 3. Otomotiv sektöründe kullanılan çeşitli magnezyum alaşımları [69,70]

\begin{tabular}{|l|l|l|l|}
\hline \multicolumn{1}{|c|}{ ALAŞIM } & \multicolumn{1}{c|}{ AZ91D } & \multicolumn{1}{c|}{ AM50A } & \multicolumn{1}{c|}{ AM60B } \\
\hline Alüminyum (\%) & $8,5-9,5$ & $4,5-5,3$ & $5,6-6,4$ \\
\hline Manganez (\%) & $0,17-0,3$ & $0,28-0,50$ & $0,26-0,50$ \\
\hline Çinko (Zn) (\%) & $0,45-0,9$ & $0,20 \max$ & $0,20 \max$ \\
\hline Silikon (\%) & $0,05 \max$ & $0,05 \max$ & $0,05 \mathrm{max}$ \\
\hline Bakır (\%) & $0,025 \max$ & $0,008 \max$ & $0,008 \max$ \\
\hline Nikel (\%) & $0,001 \max$ & $0,001 \max$ & $0,001 \max$ \\
\hline Demir (\%) & $0,004 \max$ & $0,004 \max$ & $0,004 \max$ \\
\hline Berilyum (\%) & $0,0005-0,0015$ & $0,0005-0,0015$ & $0,0005-0,0015$ \\
\hline Diğer (\%) & $0,01 \max$ & $0,01 \max$ & $0,01 \mathrm{max}$ \\
\hline
\end{tabular}




\section{SAVUNMA SANAYISİNDE MAGNEZYUM}

Talaşlı imalatta sadece düşük süneklikli Mg talaşlı işlenmeye uygun olmasına rağmen kolay tutuşabilirliği nedeni ile tehlike arz etmektedir. Bu özellikleri ile magnezyum savunma sanayisinde de önemli ve kritik kullanım alanlarına sahip olmaktadır. Büyük tahrip gücüne sahip mühimmatlarda, radar donanımlarında, portatif yer donanımlarında ve stingray torpidolarında alevlendirme amaçlı kullanılmaktadır. Çubuk şeklinde ekstrüze edilmiş magnezyum ise, anti tank mühimmatı olarak kullanılmaktadır. Standart $120 \mathrm{~mm}$ veya $100 \mathrm{~mm}$ lik mermileri ateşleme de mühimmata destekleyici olarak magnezyum katılmaktadır. Bu amaçla AZ80, AZ61 ve AZM alaşımlarının tozlarından faydalanılmaktadır. Ayrıca Mg yandığında beyaz ışık ve yoğun ısı ortaya çıkarır. İnce ve atomize tozlar alevlendirici ve ordu donatım malzemesi olarak özellikle tehlike işareti ve aydınlatma amaçlı kullanılmaktadır. Askeri helikopterler ve uçakların korunmasında hedef yanıltma amaçlı olarak Mg esaslı aygıtlar kullanılmaktadır. Ayrıca paraşütle atlayışlarda yerin görselleştirilmesinde bu aydınlatmalardan faydalanılmaktadır [71,72].

\section{SONUÇLAR}

Ulusal havacılık endüstrimizin gelişebilmesi için yeni teknolojileri uygulamaya koymak gerekmektedir. Yeni malzemeler bu teknolojik gelişimin çok önemli bir parçasıdır. Hava araçları en büyük enerji tüketicisi olup, uçuş maliyetini azaltmak için en kolay ve uygun çözüm ağırlığı azaltmak olmaktadır. Günümüzde çelik ve dökme demir yerine kullanılabilecek en uygun malzemeler $\mathrm{Al}, \mathrm{Mg}$ ve Ti alaşımlarıdır. Magnezyum alaşımları henüz havacılık sektöründe yeteri kadar kullanılmamaktadır. Son yıllarda yeni şekillendirme yöntemlerinin geliştirilmesiyle, şekillendirme kabiliyetinde iyileşmeler görülmüştür. $\mathrm{Bu}$ olumlu gelişmeler de yeni araştırmaların yapılması gerektirmektedir. Ülkemizde ise bu alanda yapılan çalışmalar yeterli olmayıp gerekli çalışmaların bir an önce yapılması zorunluluk arzetmektedir.

\section{TEŞEKKÜR}

Çalışmamızı inceleyen ve düzeltmelerde bulunan Prof. Dr. Ali Arslan KAYA hocamıza en içten teşekkürlerimizi sunarız.

\section{KAYNAKLAR}

[1] Mordike B.L., Ebert T., Magnesium Properties-Applications-Potential, Mat. Sci. Eng. A, 302, p: 37-45, 2001.

[2] Benedyk J.J., Magnesium Challenges Aluminum Dominance as the Light Metal of Choice in Automotive Markets, Light Metal Age-The International Magazine of Light Metal Industry, October 2004.

[3] American Society for Testing and Materials-ASM, Metal Handbook, Forming and Forging, 14, p: 791-804, 9th Edition, 1988.

[4] Kaya A. A., Özdoğru E.F., Abanoz D., Yiğit S., Yücel O., Otomotivde Magnezyum Alaşım Uygulamaları, OTEKON'02, Otomotiv Teknolojileri Kongresi, Bursa, 24-26 Haziran 2002.

[5] Duygulu Ö., Oktay G., Kaya A.A., The Use of Magnesium Alloys in Automotive Industry, OTEKON'06, Otomotiv Teknolojileri Kongresi, Bursa, 26-28 Haziran 2006.

[6] Kaya A.A., Pekgüleryüz M., Türkoğlu S., Özdoğru E.F., Ağırlık Tasarrufu Amacıyla Otomobil Motor Bölmesinde Magnezyum Alaşımlarının Kullanımı, OTEKON'04, Otomotiv Teknolojileri Kongresi, Bursa, 2123 Haziran 2004.

[7] Fredrich H., S. Schumann, Research for a New Age of Magnesium in the Automotive Industry, J. Mat. Proc. Tech., 117, p: 276-28, 2001.

[8] Furuya H., Kogiso N., Matunaga S., Senda K., Applications of Magnesium Alloys for Aerospace Structure Systems, Materials Science Forum, p: 341-348, 350-351, 2001.

[9] Froes F.H., Eliezer, D., Aghion, E., The Science, Technology, and Applications of Magnesium. J. Mat. Proc. Tech., 50 (9), p: 30-34, 1998.

[10] Chaffin G.N., J.E. Jacoby, Guidelines for Aluminum Sow Casting and Charging, The Aluminum Association, Washington, D.C.,1998. 
[11] Gray J.E., Luan B., Protective Coatings on Magnesium and its Alloys-A Critical Review, J. Alloys Compd., 336, p: 88-113, 2002.

[12] Kaya R.A., Çavuşoğlu H., Tanık C., Kaya A. A., Duygulu Ö, Mutlu Z., Zengin E., Aydın Y., The Effects of Magnesium Particles on Posterolateral Spinal Fusion: An Experimental in Vivo Study in a Sheep Model, J. Neurosurg-Spine, 6, p: 141-149, 2007.

[13] Duygulu O., Kaya R.A., Oktay G. and Kaya A.A., Investigation on the Potential of Magnesium Alloy AZ31 as a Bone Implant, Materials Science Forum, 546-549, p: 421-424, 2007.

[14] Duygulu O., Kaya R.A., Oktay G., Berk C., and Kaya A.A., Can Magnesium Alloys be Used as Implants?SEM Examinations from an in Vivo Study, $16^{\text {th }}$ International Microscopy Conference, Sopporo, Japan, September 2006.

[15] Kaya A.A., Future of Magnesium: Applications in Transportation and Bone Surgery, $10^{\text {th }}$ Int. Symposium on Advanced Materials (ISAM-2007), Islamabad, Pakistan, September 3-7, 2007.

[16] Kaya A.A., Kaya R.A., Witte F., and Duygulu Ö., Useful Corrosion- Potential of Magnesium Alloys as Implants, International Corrosion Engineering Conference, Seoul, Korea, May 20-24, 2007.

[17] Lu L., M.O. Lai, Y.H. Toh, L. Froyen, Structure and Properties of Mg-Al-Ti-B Alloys Synthesized via Mechanical Alloying, Mater. Sci. Eng. A, 334, p: 163-172, 2002.

[18] Rudd A.L., Breslina C.B., Mansfeld F. ,The Corrosion Protection Afforded by Rare Earth Conversion Coatings Applied to Magnesium, Corros. Sci., 42, p: 275-288, 2000.

[19] Wang Y., Wang Q., Ma C., Ding W., Zhu, Y., Effects of Zn and Re Additions on the Solidification Behavior of Mg-9Al Magnesium Alloy, Mater. Sci. and Eng. A, 342, p: 178-182, 2003.

[20] Zhang Z., Couture A., An Investigation of the Properties of Mg-Zn-Al Alloys, Scripta. Mater., 39(1), p: 45$53,1998$.

[21] Levi G., Kaplan W.D., Bamberger M., Interfacial Phenomena and Microstructure Evolution During Solidification of Binary and Ternary Al-Mg-Si Alloys Cast with Titanium Carbonitride, Mater. Sci. Eng. A, 326, p: 288-296, 2002.

[22] Suzuki M., Sato H., Maruyama K., Oikawa H., Creep Behavior and Deformation Microstructures of Mg-Y Alloys at $550 \mathrm{~K}$, Mater. Sci. Eng A, p: 252 248-255, 1998.

[23] Nishida M., Kawamura Y., Yamamuro T., Formation Process of Unique Microstructure in Rapidly Solidified Mg97Zn1Y2 Alloy, Mater. Sci. Eng A, p: 375-377, 1217-1223, 2004.

[24] Barnett M.R., Nave M.D., Bettles C.J., Deformation Microstructures and Textures of Some Cold Rolled Mg Alloys, Mater. Sci. Eng A, 386, p: 205-211, 2004.

[25] Murai T., Matsuoka S., Miyamoto S., Oki Y., Effects of Extrusion Conditions on Microstructure and Mechanical Properties of AZ31B Magnesium Alloy Extrusions, J. Mat. Proc. Tech., 141, p: 207-212, 2003.

[26] Kim W.J., An C.W., Kim Y.S., Hong S.I., Mechanical Properties and Microstructures of an AZ61 Mg Alloy Produced by Equal Channel Angular Pressing, Scripta. Mater., 47, p: 39-44, 2002.

[27] Liu S.Y., Hu J.D., Yang Y., Guo Z.X., Wang H.Y., Microstructure Analysis of Magnesium Alloy Melted by Laser Irradiation, Appl. Surf. Sci., 252, p: 1723-1731, 2005.

[28] Somasekharan A.C., Murr L.E., Microstructures in Friction-Stir Welded Dissimilar Magnesium Alloys and Magnesium Alloys to 6061-T6 Aluminum Alloy, Mater. Charact., 52, p: 49-64, 2004.

[29] Svoboda M., Pahutova M., Kucharova K., Sklenicka V., Langdon T.G., The Role of Matrix Microstructure in The Creep Behaviour of Discontinuous Fiber-Reinforced AZ 91 Magnesium Alloy, Mater. Sci. Eng A, 324, p: 151-156, 2002.

[30] Unigovski Y., Keren Z., Eliezer A., Gutman E.M., Creep Behavior of Pure Magnesium and Mg-Al Alloys in Active Environments, Mater. Sci. Eng A, 398, p: 188-197, 2005.

[31] Unigovski Y., Gutman E.M., Koren Z., Rosenson H., Hao Y., Chen T., Effect of Processing on StressCorrosion Behavior of Die-Cast Mg-Al Alloy, J. Mat. Proc. Tech., 208, p: 395-399, 2008.

[32] Gutman E.M., Mechanochemistry of Solid Surfaces, World Scientific, New Jersey, Singapore, London, p: 322, 1994.

[33] Koren Z., Rosenson H., Gutman E.M., Unigovski Y., Eliezer A., Development of Semisolid Casting for AZ91 and AM50 Magnesium Alloys, J. Light Metals, 2, p: 81-87, 2002.

[34] Mathieu S., Rapin C., Hazan J., Steinmetz P., Corrosion Behaviour of High Pressure Die-Cast and SemiSolid Cast AZ91D Alloys. Corr. Sci., 44 (12), p: 2737-2756, 2002.

[35] Stephens R.I., Schrader C.D., Lease K.B., Corrosion Fatigue of AZ91E-T6 Cast Magnesium Alloy in a 3.5 Percent $\mathrm{NaCl}$ Aqueous Environment, J. Eng. Mater. Technol., 117, p: 293-298, 1995.

[36] Unigovski Y., Keren Z., Gutman E.M., Environment-Enhanced Creep Behavior of Stainless Steel. In: 
Section 2: Materials Science, Proceedings of the International Conference on Materials Science and Engineering, BRAMAT 2005, Transilvania University of Brasov, Brasov, Romania, February 24-26, 2005.

[37] Gutman E.M., Unigovski Y., Levkovitch M., Karen Z., Porosity and Casting Condition Influence on Creep of Die-Cast Mg-Alloy. J. Mater. Sci. Lett., 17, p: 1787-1789, 1998.

[38] Gutman E.M., Unigovski Y., Eliezer A., Abramov E., Corrosion-Creep of Magnesium and Die-Cast Magnesium Alloys. J. Mater. Sci. Lett., 20, p: 1541-1543, 2001.

[39] Zhu S.M., Mordike B.L., Nie J.F., Creep Properties of a Mg-Al-Ca Alloy Produced by Different Casting Technologies, Mater. Sci. Eng. A, 483-484, p: 583-586, 2006.

[40] Gutman E.M., Eliezer A., Unigovski Y, Abramov E., Mechanoelectrochemical Behavior and Creep Corrosion of Magnesium Alloys, Mater. Sci. Eng A, 302, p: 63-67, 2001.

[41] Gredig S., Tagliaferri S., Maciejewski M., Baiker A., In: A. Frennet, J.-M. Bastin, (Eds.), Catalysis and Automotive Pollution Control III, Elsevier, Amsterdam, Stud. Surf. Sci. Catal., 96, 285, 1995.

[42] Aghion E., Boronfin B., Eliezer D., The Role of the Magnesium Industry in Protecting the Environment, J. Mat. Proc. Tech., 117, p: 381-385, 2001.

[43] Lohmüller A., Scharrer M., Jenning R., Hilbinger M., Hartmann M., Singer R. F., Injection Molding of Magnesium Alloys, 6th International Conference Magnesium Alloys and Their Applications, Wolfburgs, 2003.

[44] Landkof B., Koren Z., Rosenson H., Research and Development of Magnesium Based MMC for Airspace Structures, Research Projects, 2000-2004.

[45] Lee S., Chen Y.H., Wang J.Y., Isothermal Sheet Formability of Magnesium Alloy AZ31 and AZ61, J. Mat. Proc. Tech., 124, p: 19-24, 2002.

[46] Chen F. K., Huang T. B., Formability of Stamping Magnesium-Alloy AZ31 Sheets, J. Mat. Proc. Tech., 142, p: 643-647, 2003.

[47] Tegenkamp C., Michailov M., Wollschlager J., Pfnur H., Growth and Surface Alloy Formation of Mg on Ag 100, Appl. Surf. Sci., 151, p: 40-48, 1999.

[48] Watanabe H., Tsutsui H., Mukai T., Kohzu M., Tnabe S., Higashi K., Deformation Mechanism in a CoarseGrained Mg-Al-Zn Alloy at Elevated Temperatures, Int. J. Plasticity, 17, p: 387-397, 2001.

[49] Kaneko J., Sugamata M., Numa M., Nishikawa Y., Takada H., Effect of Texture on the Mechanical Properties and Formability of Magnesium Wrought Materials, J. Jpn. I. Met., 64 (2), p:141-147, 2000.

[50] Mwembela A., Konopleva E.B., McQueen H.J., Microstructural Development in Mg alloy AZ31 During Hot Working, Scripta. Mater., 37 (11), p: 1789-1795, 1997.

[51] Takuda H., Fujimoto H., Hatta N., Modelling on Flow Stress of Mg-Al-Zn Alloys at Elevated Temperatures, J. Mat. Proc. Tech., 80-81, p: 513-516, 1998.

[52] Keeler S.P., Backofen W.A., Plastic Instability and Fracture in Sheets Stretched over Rigid Punches, Transactions of the American Society for Metals, 56, p: 25-48, 1963.

[53] Doege E., Sebastian W., Droder K., Kurtz G., Increased Formability of Mg-Sheets Using Temperature Controlled Deep Drawing Tools, in: M.Y. Demeri (Ed.), Innovations in Processing and Manufacturing of Sheet Materials, The Minerals, Metals and Materials Society, pp: 53-60, 2001.

[54] Ghosh S., Kikuchi N., Finite Element Formulation for Simulation of Hot Sheet Metal Forming Process, Int. J. Eng. Sci. 26 (2), p: 143-161, 1988.

[55] Bolt P.J., Werkhoven R.J., Van de Boogaard A.H., Effect of Elevated Temperature on the Drawability of Aluminum Sheet Components, in: Proceedings of the ESAFORM, p: 769-772, 2001.

[56] Anık S., Malzeme Bilgisi ve Muayenesi, 4. Baskı., p: 339-340, Birsen Yayınevi, İstanbul, 1993.

[57] Froats A., Aune T. K., Hawke D., Unsworth W., Hillis J., Corrosion of Magnesium and Magnesium Alloys, Corrosion, Metals Handbook, 13, 9th ed., 1987.

[58] Molian P.A., Surface Alloying Using Lasers. In: Sudarshan TS, Editor. Surface Modification Technologies_An engineer's Guide. NewYork: Marcel Dekker In.; p: 421-92, 1989.

[59] Kalimullin R.K, Berdnikov A.T., Increasing the Corrosion Resistance of MA21 Magnesium-Lithium Alloy by Surface Laser Treatment, Protection of Metals, 1986.

[60] Majumdar J.D., Manna I., A Mathematical Model to Predict the Thermal History and Microstructure Developed in Laser Surface Alloying, Laser. Eng., 20, pp: 171-190, 2002.

[61] Umehara H., M. Takaya, S. Terauchi, Chrome-Free Surface Treatments for Magnesium Alloy, Surf. Coat Tech., 169-170, p: 666-669, 2003.

[62] Magnesium in Space, Magnesium Elektron, Elektron Wrought Alloys, 44, 2006.

[63] Moscovitch N., Magnesium Castings for the Aviation Industry, IMA Conference, Berlin, May 2005.

[64] Coating Applications, http://www.tagnite.com/coating_applications.htm, 2006. 
[65] Wendt A., Weiss K., Ben-Dov A., Bamberger M., Bronfin B., Magnesium Castings in Aeronautics Applications-Special Requirements, Magnesium Technology, TMS-2005 Conference (The Minerals, Metals \& Materials Society), San Francisco, USA, 2005. http://idea-fp6.net, 2005.

[66] Wendt A., Weiß K., Gießsimulation für Magnesium-Leichtbauteile in der Flugzeugindustrie, Virtual Materials Processing, , Bayreuth, Germany, 02-03.11. 2004.

[67] WN M, BMW 3-Series, 1997-2005, http://www.autozine.org/html/BMW/3er.html\#R6

[68] Magnesium Elektron, Magnesium in Automotive-ELEKTRON-Diecasting Alloys, http://www.magnesiumelektron.com/data/downloads/DS475Diecastingalloys.pdf

[69] Doege E., Elend L.E., Meiners F., Comparative Study of Massive and Sheet Light Weight Components Formed of Different Light Weight Alloys for Automobile Applications, In: Proceedings of the ISATA, p: 87-94. 2000.

[70] Türkiye İstatistik Yıllığı, TC Başbakanlık Devlet İstatistik Enstitüsü, ISSN 0082-691-X, 2004.

[71] 105-mm Tank Ammunition, http://www.fas.org/man/dod-101/sys/land/105t.htm, 1998.

[72] Magnesium-Alloys and Technologies, ed: K.U. Kainer, Translation: Frank Kaiser, WILEY-VCH Verlag GmbH \& Co. KGaA., p:152, 2003. 